Research

\title{
A Plasmodium yoelii soluble factor inhibits the phenotypic maturation of dendritic cells Jamie M Orengo ${ }^{1,2}$, Kurt A Wong ${ }^{1}$, Carlos Ocaña-Morgner ${ }^{1,3}$ and Ana Rodriguez*1
}

Address: ${ }^{1}$ New York University School of Medicine, Department of Medical Parasitology, 341E. 25th St. New York, NY 10010, USA, 2 Regeneron Pharmaceuticals, Inc. 777 Old Saw Mill River Road, Tarrytown, NY 10591, USA and 3Institute of Physiological Chemistry, Medical School, MTZ, Dresden University of Technology, Fiedlerstr. 42, 01307 Dresden, Germany

Email: Jamie M Orengo - Jamie.Orengo@regeneron.com; Kurt A Wong - kurt.wong@nyumc.org; Carlos Ocaña-Morgner - Carlos.OcanaMorgner@mailbox.tu-dresden.de; Ana Rodriguez* - ana.rodriguez@nyu.edu

* Corresponding author

Published: 15 December 2008

Malaria Journal 2008, 7:254 doi:10.1 I86/I475-2875-7-254

This article is available from: http://www.malariajournal.com/content/7/I/254

(C) 2008 Orengo et al; licensee BioMed Central Ltd.

This is an Open Access article distributed under the terms of the Creative Commons Attribution License (http://creativecommons.org/licenses/by/2.0), which permits unrestricted use, distribution, and reproduction in any medium, provided the original work is properly cited.
Received: 13 June 2008

Accepted: 15 December 2008

\begin{abstract}
Background: Infection with the protozoan parasite Plasmodium is the cause of malaria. Plasmodium infects host erythrocytes causing the pathology of the disease. Plasmodium-infected erythrocytes can modulate the maturation of dendritic cells (DCs) and alter their capacity to activate $T$ cells.

Methods: Mice infected with Plasmodium yoelii and isolated P. yoelii-infected erythrocytes were used to study their effect on the maturation of mouse dendritic cells.

Results: DCs are not able to mature in response to LPS injection during the late stage of $P$. yoelii infection in mice, indicating impaired functionality of these cells in vivo. P. yoelii- infected erythrocytes inhibit the maturation of DCs in vitro in a dose-dependent manner, which is consistent with the inhibition found during late infection when parasite burden is highest. The inhibition of DC maturation and the cytokine secretion profile of DCs are modulated by soluble factors released by $P$. yoelii-infected erythrocytes. A small, heat-stable, non-hydrophobic molecule of $P$. yoelii-infected erythrocytes rapidly inhibits the LPS induced phenotypic maturation of DCs in a reversible manner.

Conclusion: These findings add evidence to the malaria associated immune suppression in vivo and in vitro and provide insight into the nature and mechanism of the Plasmodium factor(s) responsible for altering DC functions.
\end{abstract}

\section{Background}

The interactions of the Plasmodium parasite with the immune system of the host are complex in many aspects regarding the activation and regulation of different types of immune cells. The specific characteristics of the immune response may contribute to the successful persistence of the parasite and the slow generation of immunity against the disease that is observed in endemic areas
[1]. Inhibition of specific $T$ cell responses to malaria antigens and $\mathrm{T}$ cell depletion have been identified in individuals infected with malaria [2-5]. Immune suppression does not appear to affect only anti-Plasmodium responses, but the parasite can also inhibit immune responses to other organisms. In fact, malaria is associated with a higher incidence of other infectious diseases [6-8] and reduced immune responses to vaccinations $[9,10]$. Studies 
using in vitro P. falciparum cultures or in vivo murine models with different Plasmodium strains have shown that infection is associated with altered macrophage [11-15] and dendritic cell (DC) responses [16-25]. However, other studies have found normal DC responses to Plasmodium [26-31].

DCs are antigen presenting cells that play a pivotal role in the initiation of immune responses, as they form a bridge between the innate and adaptive immune responses and possess the unique capacity to initiate primary immune responses via the activation of naïve T cells [32]. Pathogens frequently undermine the immune system by modulating the ability of DCs to initiate an immune response [33]. The maturation and function of monocyte-derived human DCs are modulated by $P$. falciparum-infected erythrocytes in vitro $[16,18,34]$. This phenotype is also supported with field evidence since peripheral blood DCs from children with acute $P$. falciparum infection showed low expression levels of human leukocyte antigen (HLA)DR on their surface $[35,36]$, suggesting the functional impairment of these DCs. Given the crucial role of DCs in both the innate and adaptive immune responses, modulation of DC functions may provide some explanation as to why protective immunity to malaria is slow to develop.

Using a murine malaria model, it was tested if parasite infection affects the capacity of DCs to respond to another stimulus in vivo and observed that the parasite inhibits the phenotypic maturation of splenic DCs in response to lipopolysaccharide (LPS). The P. yoelii inhibition of phenotypic DC maturation was dose dependent and contact independent, which is consistent with previous findings using the human in vitro model [34]. The culture medium of $P$. yoelii-infected erythrocytes inhibits LPS-induced maturation of DCs and performed the biochemical characterization of a $P$. yoelii factor(s) responsible for this activity.

\section{Methods}

\section{Reagents, mice and parasites}

All chemical reagents were from Sigma unless otherwise specified. All antibodies for flow cytometry were purchased from BD Biosciences. The parasite used was $P$. yoelii 17X NL. Female, 6-8 week old Swiss Webster (SW) or $\mathrm{BALB} / \mathrm{C}$ mice were purchased from Taconic or the National institutes of Health (NIH). Monosodium urate crystals were prepared as previously described [37].

\section{Isolation of CDI I c DC from P. yoelii-infected mice}

For the initiation of parasite infection, mice were injected intraperatonealy (I.P.) with $10^{6}$ infected erythrocytes. To evaluate parasitaemia the number of parasitized erythrocytes from 500 cells in a Giemsa-stained thin blood smear was calculated.
In vivo maturation of CD $11 \mathrm{c}^{+}$cells was induced by intravenous injection (I.V.) of $25 \mu \mathrm{g} /$ mouse of lipopolysaccharide (LPS) from Salmonella typhimurium diluted in PBS 24 hours before isolation of $\mathrm{CD}_{1} 1 \mathrm{c}^{+}$splenocytes. Control mice were injected with the same volume of PBS.

Whole spleens were aseptically removed from euthanized mice and splenocytes were obtained by mechanical disruption through a cell strainer. Erythrocytes were lysed by incubation with ammonium chloride/potassium hydrogen carbonate buffer $\left(155 \mathrm{mM} \mathrm{NH}_{4} \mathrm{CL}, 1 \mathrm{mM} \mathrm{KHCO}_{3}, 0.1\right.$ $\mathrm{mM} \mathrm{Na} \mathrm{EDDT}_{2}$ ) for five minutes followed by washing with cold DMEM (Mediatech) supplemented with 10\% FBS (Invitrogen Life Technologies) and PSG antibiotic mix (100 U/ml penicillin, $100 \mathrm{ug} / \mathrm{ml}$ streptomycin and $2 \mathrm{mM}$ L-glutamine; Invitrogen Life Technologies). Cells were kept on ice at all times. CD11c+ splenocytes were obtained by positive selection using anti-CD11c antibodies and MACS magnetic columns (Miltenyi Biotec) according to the manufacturer's instructions. After isolation, cells were washed, stained with the appropriate antibodies, and assayed via flow cytometry for the expression of co-stimulatory molecules.

\section{Flow cytometry analysis}

Prior to staining, DCs were incubated with anti-CD16/ CD32 (FCyIII/II receptor; $2.4 \mathrm{G}$ ) for 5 minutes on ice to prevent the binding of antibodies to Fc receptors. For analysis, the following antibodies were used: PE antiCD11c (HL3), FITC anti-CD40 (3/23) and FITC antiCD86 (GL1). All antibodies were used at a 1:100 dilution in PBS $+10 \%$ FBS and cells were kept on ice during the staining procedure. Flow cytometric analysis was performed using a FACSCalibur (BD Biosciences) and CellQuest (BD Biosciences) or FlowJo (Tree Star) software.

\section{Isolation of erythrocytes from Plasmodium-infected mice}

Whole blood was isolated from infected or uninfected anesthetized SW mice via cardiac puncture and diluted in $100 \mathrm{U}$ heparin/ml PBS. Erythrocytes were washed 3 times with PBS and separated from plasma and white blood cells by centrifugation at $1,800 \mathrm{~g}$ for 5 minutes. The buffy coat was removed by pipetting. Erythrocytes were either used as prepared or further processed depending on the experiment.

\section{Separation of schizonts from $\mathbf{P}$. yoelii-infected blood}

Washed infected erythrocytes were separated into schizont and non-schizont stages by centrifugation using a 53\% Accudenz density gradient solution in PBS (Accurate Chemical and Scientific Corp). Uninfected erythrocytes from a matched mouse were treated in the same way. The purified schizonts or uninfected erythrocytes were centrifuged at 1,800 $\mathrm{g}$ for 5 minutes and washed twice with PBS. 
This procedure results in preparations with higher than $85 \%$ schizonts.

\section{Preparation of the conditioned medium of P. yoelii- infected erythrocytes}

The conditioned medium was prepared as previously described [38]. Briefly, a culture containing 30\% schizonts and $70 \%$ of non-schizont stages from a $P$. yoelii infected mouse was incubated in DMEM supplemented with antibiotic mix at a density of $5 \times 10^{8} / \mathrm{ml}$ for $48 \mathrm{~h}$ at $37^{\circ} \mathrm{C}, 5 \% \mathrm{CO}_{2}$. Cultures were centrifuges at $1,800 \mathrm{~g}$ for 5 minutes to collect the supernatant. This supernatant was heated to $100^{\circ} \mathrm{C}$ for 5 minutes, centrifuged at $1,800 \mathrm{~g}$ for 5 minutes and filtered through a $0.2 \mu \mathrm{m}$ diameter filter. A control conditioned medium was prepared in parallel using erythrocytes from an uninfected mouse. To mimic the conditions of schizont lysis in the infected erythrocytes preparation, a proportion of erythrocytes was separated and lysed by hypo-osmotic treatment with water. Osmolarity was restored and a culture containing 30\% lysed uninfected erythrocytes and 70\% intact uninfected erythrocytes were incubated in DMEM in the same conditions described for the infected conditioned medium. In all experiments, $10 \%$ FBS was added to the conditioned medium prior to its addition to DCs.

\section{Incubation of DCs with P. yoelii-infected erythrocytes or} the conditioned medium of $P$. yoelii-infected erythrocytes Murine myeloid bone marrow-derived DCs were differentiated as previously described [38]. Briefly, bone marrow precursors from femurs and tibias of BALB/c mice were cultured in Petri dishes for $7-10$ days at $37^{\circ} \mathrm{C}, 5 \% \mathrm{CO}_{2}$ in DMEM supplemented with antibiotic mix, 10\% FBS, and $30 \%$ conditioned medium of the myeloma cell line Ag8653 that expresses recombinant granulocyte monocyte-colony stimulating factor (GMCSF) [39]. This procedure results in preparations with higher than $90 \%$ CD $11 \mathrm{c}^{+}$ cells, which also present surface CD40, CD80, CD86 and MHC-I and II molecules, which are up-regulated in response to LPS [40].

For experiments involving DC cultured with erythrocytes, DCs $\left(10^{6} / \mathrm{ml}\right)$ were incubated with uninfected or P. yoeliiinfected erythrocytes at a ratio of 30:1 (iRBC:DC) unless otherwise indicated. Cells were cultured in DMEM supplemented with antibiotic mix, 10\% FBS and 5\% GM-CSF for 24 hours at $37^{\circ} \mathrm{C}, 5 \% \mathrm{CO}_{2}$. DCs were then induced (or not) to mature with $100 \mathrm{ng} / \mathrm{ml}$ LPS and incubated for an additional 24 hours. Erythrocytes were lysed with ammonium chloride/potassium hydrogen carbonate buffer for 5 minutes. DCs were washed and resuspended in PBS $+10 \%$ FBS and stained with the appropriate antibodies for analysis of co-stimulatory molecules by flow cytometry.

For experiments involving DC cultured with the conditioned medium of $P$. yoelii-infected erythrocytes, DCs $\left(10^{6} / \mathrm{ml}\right)$ were incubated with the conditioned medium for the indicated amount of time and then incubated with $100 \mathrm{ng} / \mathrm{ml} \mathrm{LPS} \mathrm{for} \mathrm{an} \mathrm{additional} 24 \mathrm{~h} 37^{\circ} \mathrm{C}, 5 \% \mathrm{CO}_{2}$. DCs were harvested, washed, resuspended in PBS $+10 \%$ FBS, and stained with the antibodies for analysis of co-stimulatory molecules using flow cytometry.

Incubation media from DC-conditioned media co-cultures was collected and assayed by ELISA for the secretion of IL-6 or IL-12 p70 (OPTI-EIA kit, BD biosciences) or $\mathrm{PGE}_{2}$ (Cayman Chemicals)

\section{Characterization and molecular identification of $\mathbf{P}$. yoelii active molecules}

Size fractionation of the conditioned media using Centricon ${ }^{\circledR}$ columns The conditioned media of uninfected- or P. yoelii-infected erythrocytes was fractionated using Centricon ${ }^{\circledR}$ (Millipore) filters of various membrane sizes according the manufacturers instructions. Briefly, centrifugal force drives the separation of solvents and solutes through the membrane filters of varying sizes into the filtrate vial. The conditioned medium was spun on the Centricon ${ }^{\circledast}$ column at $1,800 \mathrm{~g}$ for 90 minutes. The column flow through was collected and used in assays with DCs.

\section{Dialysis of the conditioned medium using Tube-O-Dialyzers}

Using Tube-O-Dialyzers (Geno Technology, Inc) with a molecular weight cut off of $1 \mathrm{kDa}$, molecules that were smaller than $1 \mathrm{kDa}$ were dialyzed out of the conditioned medium of uninfected- or $P$. yoelii-infected erythrocytes that were each previously size fractionated to smaller than $3 \mathrm{kDa}$. Samples were dialyzed against DMEM (1:100 vol:vol) for 8 hours and the DMEM was changed every 2 hours.

\section{Treatment with DNase I}

DNase I (EMD Biosciences) was resuspended in DMEM, without serum, at $10 \mathrm{mg} / \mathrm{ml}$. Endotoxin was removed from DNase I using the EndoClean kit (BioVintage) according to the manufacturer's protocol. Then the DNase I was added to the conditioned media $(1 \mu \mathrm{g} / \mathrm{ml})$ and incubated at $37^{\circ} \mathrm{C}$ for $2 \mathrm{~h}$. The DNase I was deactivated by boiling the $\mathrm{CM}$ for 10 minutes.

\section{Purification using Sep-Pak ${ }^{\circledR}$ reversed phase columns}

The conditioned medium of uninfected- or $P$. yoeliiinfected erythrocytes was passed through Sep-Pak ${ }^{\circledR}$ reverse phase columns that retain hydrophobic molecules. The Sep-Pak ${ }^{\circledast}$ columns were pre-rinsed with $10 \mathrm{mls}$ of $100 \%$ ethanol followed by $10 \mathrm{mls}$ of $0.1 \%$ acetic acid. The conditioned media was passed through the column and the flow through containing non-hydrophobic molecules was dried and reconstituted in DMEM without salts. The conditioned medium containing hydrobic molecules was eluted with $70 \%$ ethanol, dried, and reconstituted in DMEM. 


\section{Statistical analysis}

All data were analysed using GraphPad Prism software. Significant differences were determined using student's ttests or one-way ANOVA. Data were considered significant if $\mathrm{p}<0.05$.

\section{Results \\ Plasmodium yoelii infection inhibits the in vivo maturation of CDI I c splenocytes}

The ability of splenic CD $11 \mathrm{c}^{+}$cells (myeloid DCs) from $P$. yoelii-infected Swiss Webster (SW) mice to respond to a maturation stimulus during late infection in vivo was tested. The surface expression of the co-stimulatory molecules CD40 and CD86 was measured as an indication of DC maturation [41]. As reported before for late $P$. yoelii infection $[17,19,42]$, the expression of CD40 and CD86 on $\mathrm{CD} 11 \mathrm{c}^{+}$splenocytes was not significantly upregulated in response to parasite infection (average parasitaemia, 21.62). When the response to LPS that was injected into the mice 24 h before was analyzed, CD11 $\mathrm{c}^{+}$splenocytes from infected mice did not up-regulate the co-stimulatory molecules CD40 and CD86 (Figure 1). Whereas CD11 $\mathrm{c}^{+}$ splenocytes from control uninfected mice increased the expression of these co-stimulatory molecules in response to LPS. These results suggest that infection with $P$. yoelii inhibits $\mathrm{CD} 11 \mathrm{C}^{+}$responses to other maturation stimuli, such as LPS. It is important to note that during late P. yoelii infection the regulatory DC subset is the dominant DC population in the spleen, therefore the data presented here mainly reflect the behavior of this population[42].

In vitro inhibition of DC maturation is dose-dependent Plasmodium falciparum and $P$. yoelii-infected erythrocytes inhibit the LPS induced upregulation of histocompatibility and co-stimulatory molecules on DCs in vitro $[16,17]$. Furthermore, it was shown using the human in vitro model that this inhibition was dose dependent [34]. P. yoelii-infected erythrocytes, when incubated with murine myeloid DCs at a ratio of 30:1, were found to inhibit the LPS induced upregulation of the co-stimulatory molecules CD40 and CD86 on DC cell surfaces (Figure 2). This failure to up-regulate co-stimulatory molecules was not observed when DCs were incubated alone or with uninfected RBCs at the same ratio. The inhibitory effect was dose-dependent and decreased at lower ratios of $P$. yoeliiinfected erythrocytes to DCs (Figure 2). This is consistent with observations using the human in vitro model [34]; however, some inhibition of co-stimulatory molecule expression at lower ratios (10:1 and 1:1 iRBC:DCs) that was not apparent in the human experiments was still observed.

Uric acid and the inhibition of DC maturation by $\mathbf{P}$. yoeliiinfected erythrocytes

DCs produce TNF in response to Plasmodium infected erythrocytes $[29,30,38]$. The $P$. yoelii factor that induces
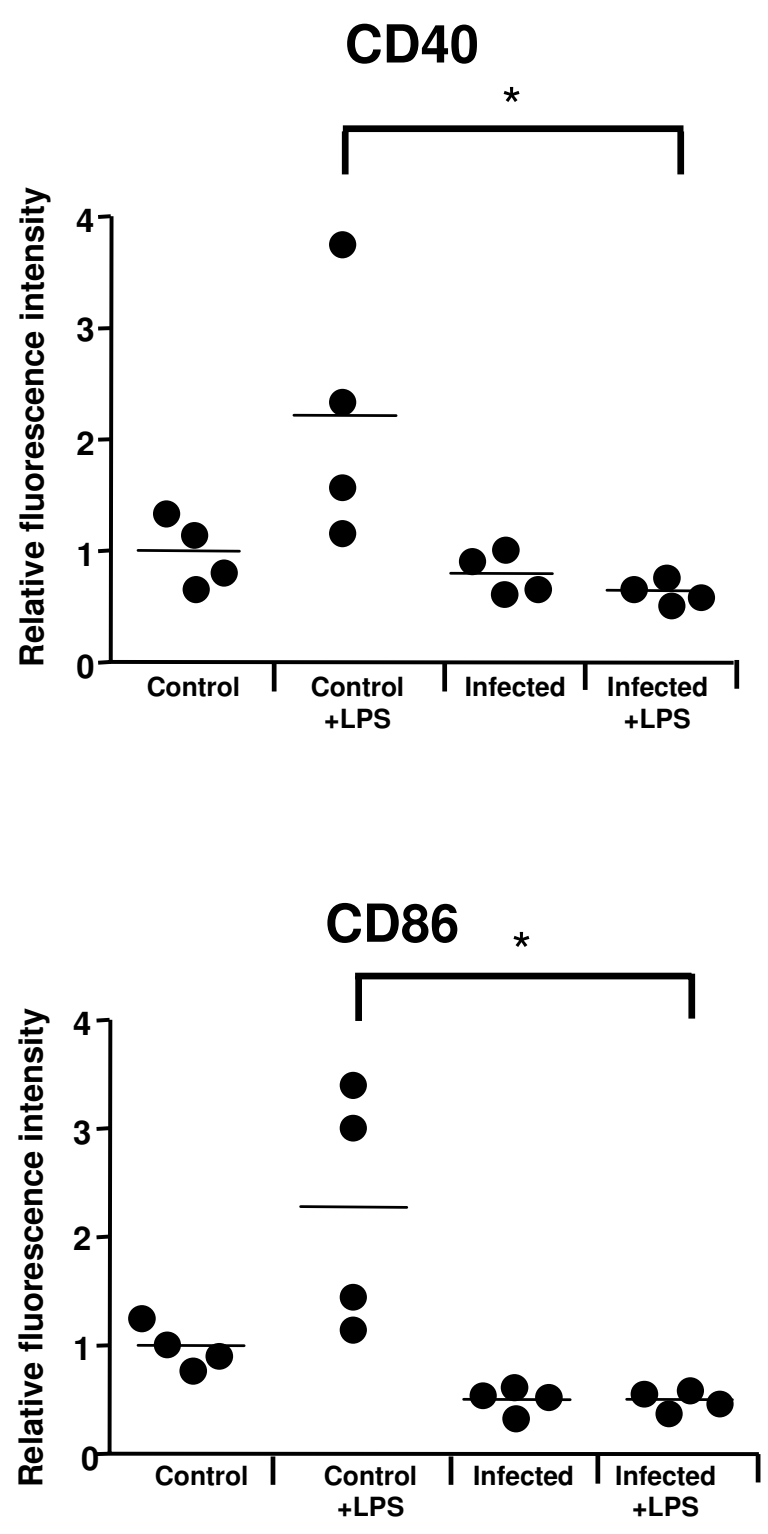

Figure I

$P$. yoelii infection inhibits the in vivo maturation of CDI I c splenocytes. SW mice were infected or not with $10^{6} \mathrm{P}$. yoelii-infected erythrocytes. At day 10 post infection, $\mathrm{CDI} \mathrm{Ic}^{+}$splenocytes were analysed via flow cytometry for their surface expression of co-stimulatory molecules CD40 and CD86. When indicated, $25 \mu \mathrm{g} /$ mouse of LPS was injected intravenously $24 \mathrm{~h}$ prior to spleen harvest. Results are expressed as relative fluorescent intensity for the gated CDIIc cells of each mouse compared with the average of gated $\mathrm{CDI} \mathrm{Ic}^{+}$cells from uninfected, unstimulated mice. Each symbol is representative of one mouse and each group contains at least 3 mice. Bars represent mean value of each group of mice. Differences in surface expression were considered significant when $\mathrm{p}<0.05$. * represents significant differences in surface expression when compared to LPS treated uninfected mice. 
CD40

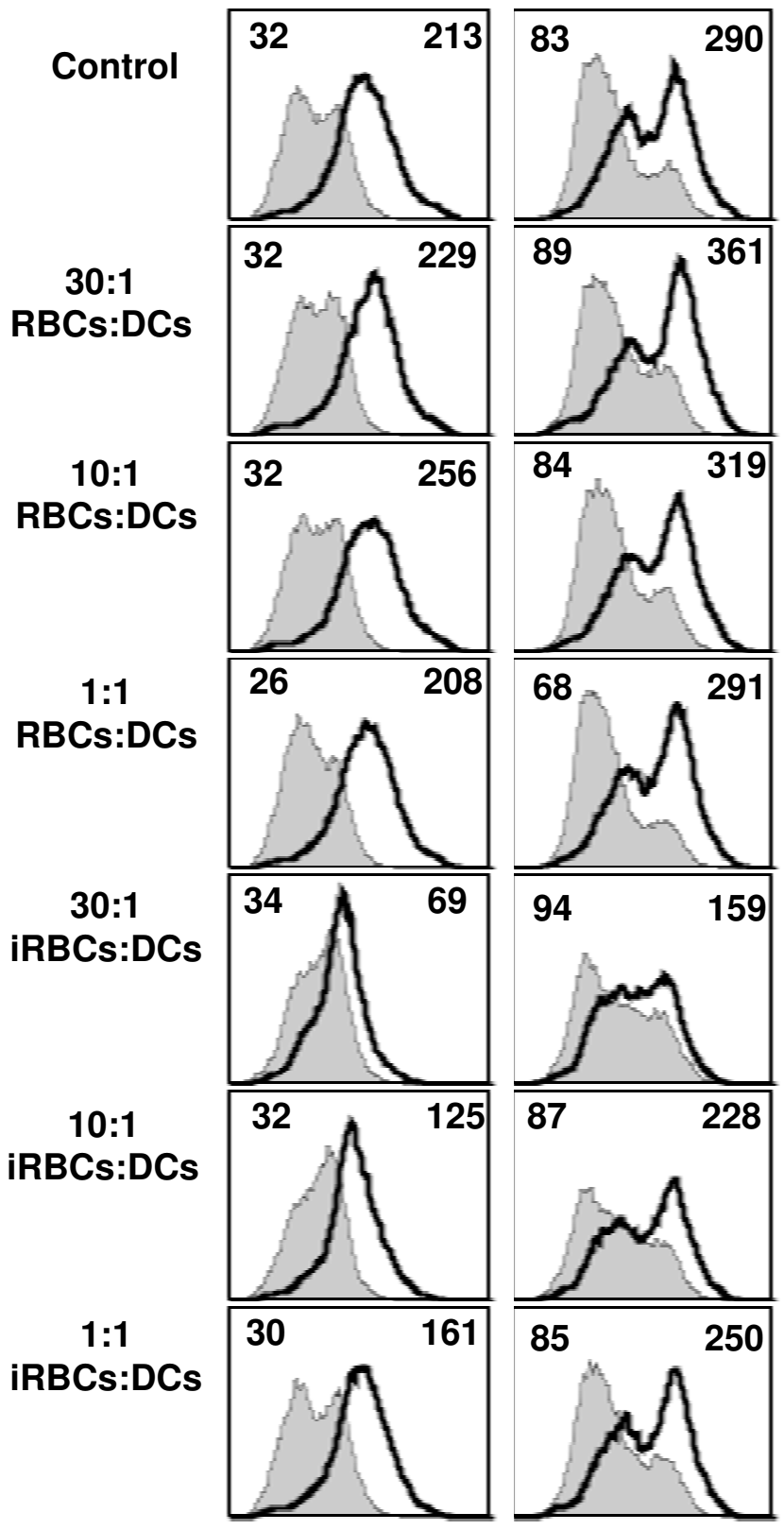

Figure 2

$P$. yoelii in vitro inhibition of DC maturation is dose dependent. DCs were incubated alone (Control), in the presence of uninfected RBCs (RBCs) or P. yoelii-infected erythrocytes (iRBCs) at the indicated ratio to DCs for $24 \mathrm{~h}$ followed by an additional $24 \mathrm{~h}$ in the presence or absence of $100 \mathrm{ng} / \mathrm{ml}$ LPS. FACS plots show CD40 and CD86 surface expression on DCs from control cultures (gray filled histograms) or incubated with LPS (black thick line). Mean fluorescent intensity (MFI) values are indicated in each plot for control and LPS stimulated. Each FACS plot is representative of one of at least 2 independent experiments.
TNF was shown to be Plasmodium-derived hypoxanthine that is converted into uric acid by xanthine oxidoreductase present in the serum [38]. Since TNF can induce the maturation of DCs [43] and it was recently shown that systemic TNF in Plasmodium-infected mice can impair DC function [25], it was tested whether hypoxanthine could also be responsible for the impaired maturation of DCs. Addition of hypoxanthine to DCs in the presence of serum results in the secretion of TNF from DCs [38], however, it did not inhibit the LPS-induced maturation of DCs (Figure 3A). At high concentrations of hypoxanthine, an increase in surface co-stimulatory molecules was observed. This is expected since the products of hypoxanthine degradation: reactive oxygen species and uric acid can both induce DC maturation [37,44]. Despite this increase in surface markers, DCs were still responsive to LPS-induced maturation (Figure 3A).

Additionally, it was tested whether the hypoxanthine or its degradation products accumulated in the conditioned medium could play a role in the inhibition of DC maturation. Allopurinol is an inhibitor of xanthine oxidoreductase that blocks hypoxanthine degradation and inhibits $P$. yoelii-induced release of TNF by DCs [38]. It was found that allopurinol did not affect $P$. yoelii-induced inhibition of DC maturation (Figure 3B). Therefore, it is unlikely that hypoxanthine or its degradation pathway are responsible for the $P$. yoelii-induced inhibition of DC maturation. On the contrary, it appears that this pathway may contribute to the maturation of DCs. It was then tested whether $P$. yoelii-infected erythrocytes could also inhibit maturation induced by uric acid. Uric acid is a danger signal that in the crystallized form increases the expression of CD86 on the surface of DCs [37]. Uric acid crystals increased the surface expression of CD86, but not of CD40. In the presence of $P$. yoelii-infected erythrocytes, the uric acidinduced upregulation of CD86 was not observed (Figure 3C).

\section{Conditioned medium from P. yoelii-infected erythrocytes inhibits DC maturation}

It has been reported using a transwell culture system that $P$. falciparum modulation of DC phenotypic maturation is not contact dependent [34], suggesting that a soluble factor(s) is responsible for the effect.

To investigate the possibility that the inhibitory effect observed is also mediated by a soluble factor, the effects of a conditioned medium of $P$. yoelii-infected erythrocytes (described in methods) was tested on DC responses to LPS. The conditioned medium of $P$. yoelii-infected erythrocytes inhibited the LPS induced up-regulation of CD40 and CD86 on the surface of DCs (Figure 4A). A conditioned medium obtained from the incubation of whole uninfected erythrocytes did not inhibit the maturation of 


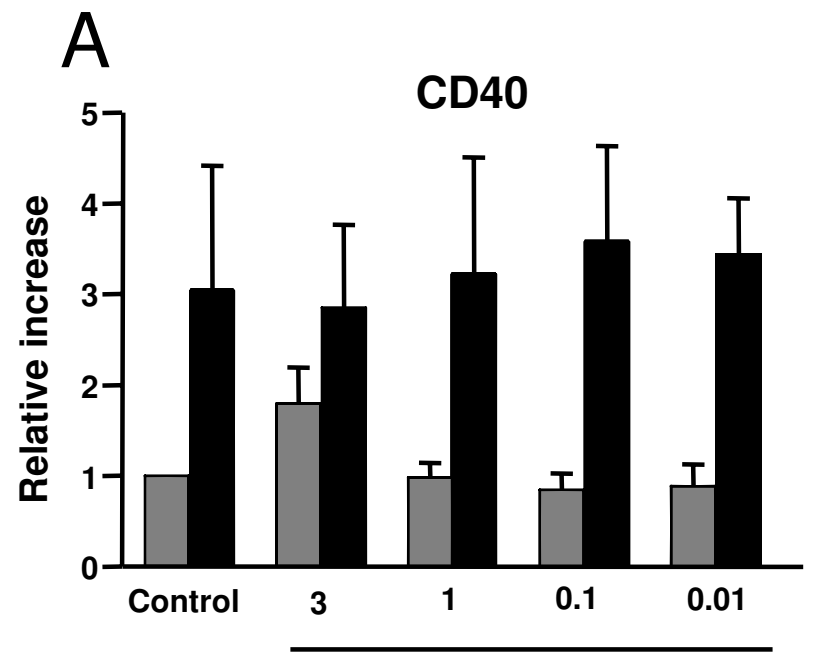

Hypoxanthine (mM)

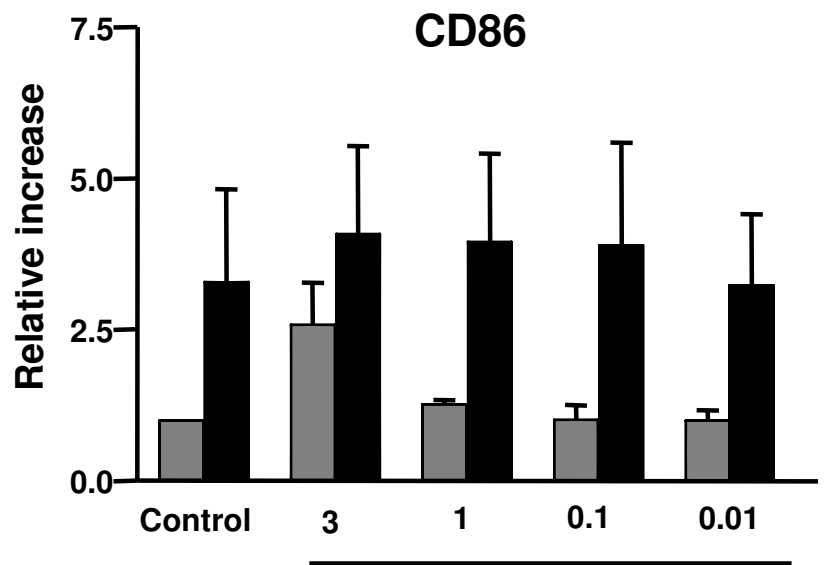

Hypoxanthine (mM)

B

Control

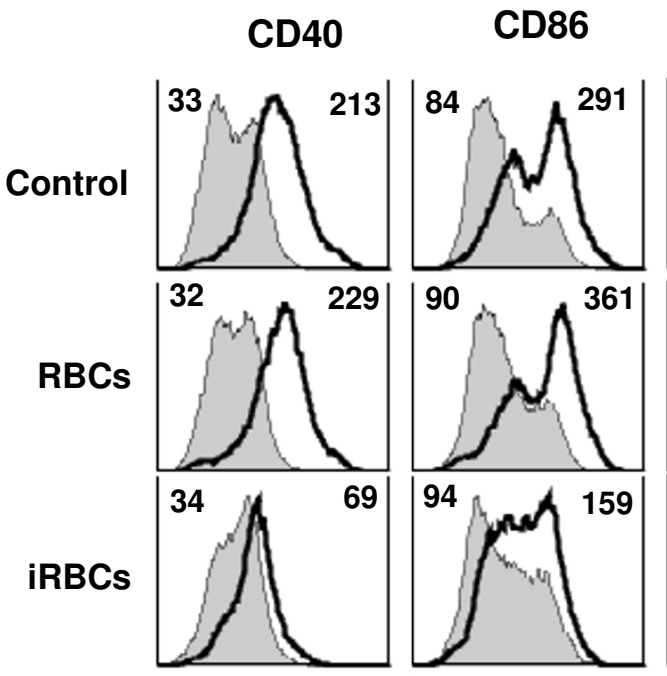

+Allopurinol CD40
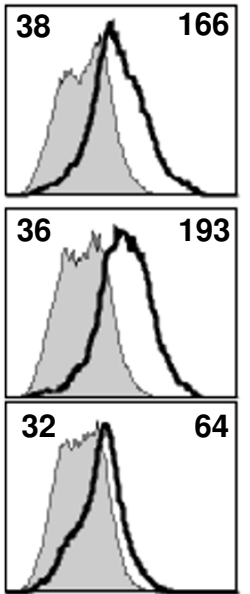

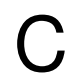

C

Uric Acid

CD86
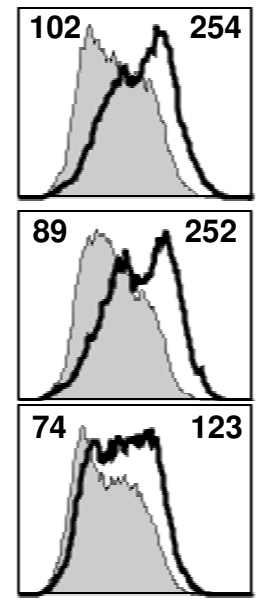
CD40
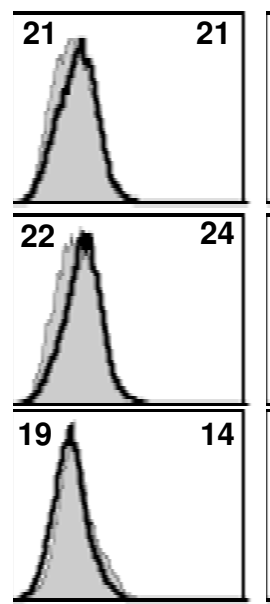

CD86

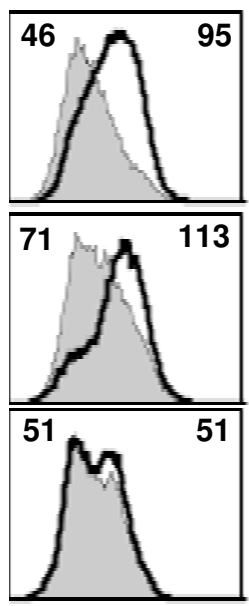

\section{Figure 3}

Uric acid and the inhibition of DC maturation by $\boldsymbol{P}$. yoelii-infected erythrocytes. (A) DCs were incubated alone (Control) or in the presence of various concentrations of hypoxanthine for $24 \mathrm{~h}$ followed by an additional $24 \mathrm{~h}$ in the absence (grey bars) or presence (black bars) of $100 \mathrm{ng} / \mathrm{ml}$ LPS. Results are expressed as the relative increase in MFI over DCs incubated in media alone. Error bars represent the standard deviation of 3 averaged independent experiments. (B, C) DCs were incubated alone (Control) or with uninfected RBCs (RBCs) or P. yoelii-infected erythrocytes (iRBCs). (B) 2 mM allopurinol was added or not to the co-cultures for $24 \mathrm{~h}$ followed by an additional $24 \mathrm{~h}$ in the presence or absence of $100 \mathrm{ng} / \mathrm{ml} \mathrm{LPS}$. (C) Cocultures were incubated alone for $24 \mathrm{~h}$ before addition of uric acid crystals for additional $24 \mathrm{~h}$. FACS plots show CD40 or CD86 surface expression on DCs from control cultures (gray filled histogram) or incubated with LPS (B) or uric acid crystals (C) (black thick line). Mean fluorescent intensity (MFI) values are indicated in each plot for control and stimulated. Each FACS plot is representative of one of at least 2 independent experiments. 
DCs. However, as a better experimental control, a proportion of the uninfected erythrocytes was lysed to account for erythrocyte factors that are released as a result of erythrocyte rupture that occurs in the infected erythrocyte preparation. This control conditioned medium did not inhibit the LPS induced upregulation of CD40 or CD86 on the surface of DCs (Figure 4A). The inhibitory effect of the conditioned medium is dose dependent (Figure 4A) and heat stable, since the inhibitory activity was not affected after boiling the conditioned medium before incubation with DCs. These results indicate that a heat-stable soluble factor(s) derived from $P$. yoelii-infected erythrocytes inhibits the maturation of DCs.

To inhibit DC maturation, P. falciparum and P. yoeliiinfected erythrocytes are pre-incubated with DCs for 20 to $24 \mathrm{~h}$ prior to the addition of a maturation stimulus $[16,17,34]$. This suggests that either the factor (s) responsible for inhibiting DC maturation requires time to reach a threshold concentration in the medium or that the DCs require time to respond to it. To prepare the $P$. yoelii-conditioned medium, parasites are incubated in media for 48 $\mathrm{h}$. This is enough time for the inhibitory factor(s) to accumulate in the medium, as evidenced by the inhibitory response obtained (Figure 4A). This experiment, however, was performed by pre-incubating the DCs with the conditioned medium for $24 \mathrm{~h}$ before adding the maturation stimulus, as was done with whole infected erythrocytes. To determine the time of action of the soluble factor(s) on DC maturation, the conditioned medium of $P$. yoelii infected erythrocytes was added to DCs at the same time as LPS. In these conditions, a strong inhibition of the LPSinduced maturation was found (Figure 4B), suggesting that the factor(s) has a rapid effect on DCs.

When DCs were pre-incubated with the conditioned medium for $24 \mathrm{~h}$, washed and then incubated with DC medium in the presence or absence of LPS for an additional $24 \mathrm{~h}$, the inhibitory effect of the conditioned medium was not observed, as these DCs upregulated CD40 and CD86 in response to LPS stimulation (Figure 4C). These data suggest that the inhibitory effect of the $P$. yoelii factor(s) on DC maturation is reversible. Since the DCs matured in response to LPS once the conditioned medium was removed, it also suggests that the $P$. yoeliisoluble factor(s) is not toxic to the DCs. It was confirmed that the conditioned medium of $P$. yoelii-infected erythrocytes did not induce DC death. Using propidium iodide exclusion to determine the percentage of live DCs, no differences were found after incubation for $48 \mathrm{~h}$ alone or with the conditioned medium from infected or uninfected erythrocytes.

\section{Conditioned medium modulates DC cytokine production} The effect of the conditioned medium of $P$. yoelii infected erythrocytes was tested on the secretion of two inflamma- tory mediators that are released by DCs in response to $P$. yoelii-infected erythrocytes: prostaglandin $\mathrm{E}_{2}\left(\mathrm{PGE}_{2}\right)$ [45] and interleukin (IL)-6 [19]. The conditioned medium of $P$. yoelii-infected erythrocytes induced DC production of $\mathrm{PGE}_{2}$ (Figure 5A) and IL-6 (Figure 5B), whereas the conditioned medium of uninfected erythrocytes did not induce the production of these inflammatory mediators. The conditioned medium of $P$. yoelii-infected erythrocytes also induces the secretion of TNF from DCs [38].

Pre-incubation of DCs with $P$. yoelii- or $P$. falciparuminfected erythrocytes does not induce IL-12 production, but instead inhibits the secretion of IL-12 in response to LPS $[17,18,34]$. The incubation of DCs with the conditioned medium of $P$. yoelii infected erythrocytes also resulted in a failure of these cells to secrete IL-12 in response to stimulation with LPS (Figure 5C). Moreover, this was a rapid inhibition, as the conditioned medium was added concurrently with LPS.

\section{Characterization of the P. yoelii soluble factor(s) that inhibits DC maturation}

To further characterize the P. yoelii factor(s) that inhibits DC maturation, the conditioned medium was fractionated by size using Centricon ${ }^{\circledR}$ filters of various membrane pore sizes prior to incubation with DCs. When the $P$. yoelii-conditioned medium was size fractionated to smaller than $30 \mathrm{kDa}, 10 \mathrm{kDa}$ or $3 \mathrm{kDa}$ there was inhibition of the LPS-induced up-regulation of CD40 and CD86 (Figure 6A). No inhibitory activity was found in the high molecular weight ( $>30 \mathrm{kDa}, 10 \mathrm{kDa}$ or $3 \mathrm{kDa}$ ) fractions.

Molecules smaller than $1 \mathrm{kDa}$ were dialyzed out from the $P$. yoelii-conditioned medium that was previously size fractionated to smaller than $3 \mathrm{kDa}$ using Tube-O-Dialyz$\mathrm{ers}^{\circledast}$ dialysis tubes. When this fractionated, dialyzed conditioned medium was incubated with DCs, the inhibitory effect was lost and the DCs up-regulated surface expression of CD40 and CD86 in response to LPS stimulation (Figure 6B), indicating that the inhibitory molecule(s) was smaller than $1 \mathrm{kDa}$. The inhibitory activity was also found not to be sensitive to extensive treatment with DNase I.

The non-hydrophobic fraction of the conditioned medium of $P$. yoelii-infected erythrocytes retained the ability to inhibit the LPS induced upregulation of CD40 and CD86 on the surface of DCs (Figure 6C). Conversely, the conditioned medium containing the hydrophobic molecules did not inhibit the LPS induced upregulation of CD40 and CD86 to the DC surface (Figure 6C).

These data suggest that a small, soluble, non-hydrophobic molecule of $P$. yoelii infected erythrocytes inhibits the LPS induced phenotypic maturation of DCs. 
A
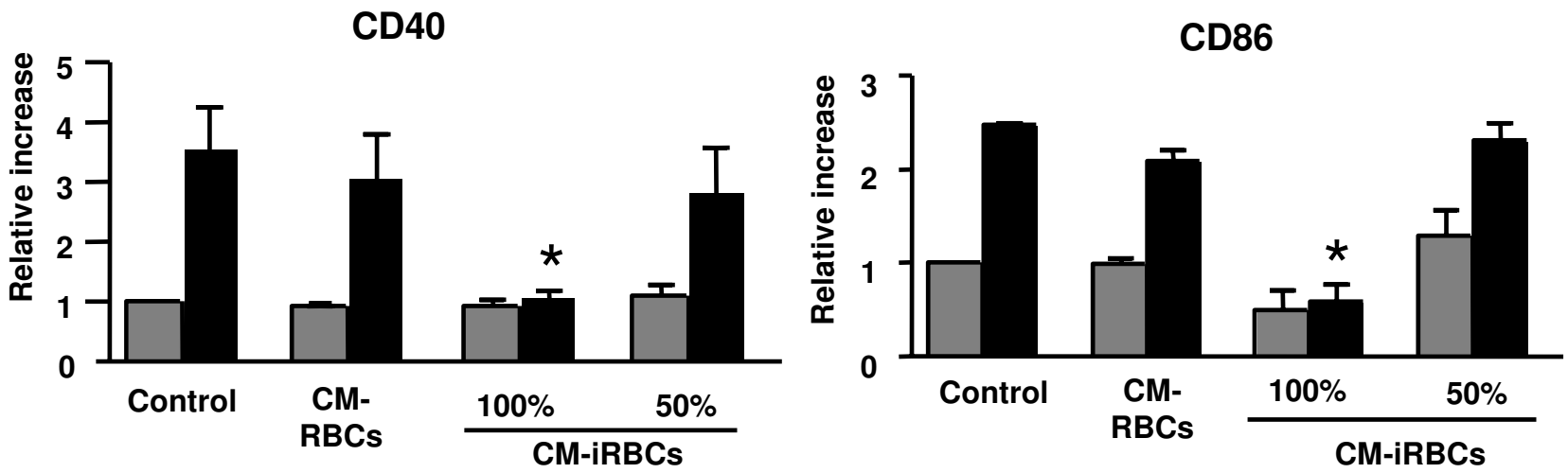

B

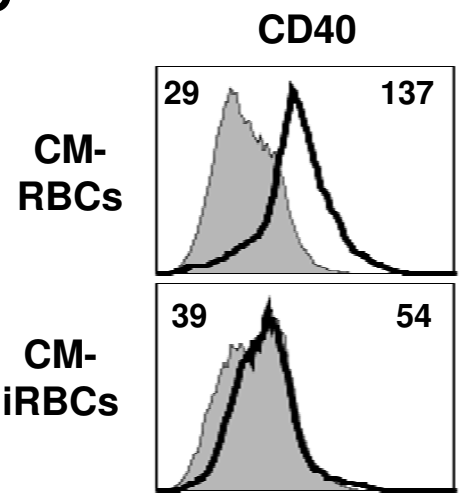

CD86

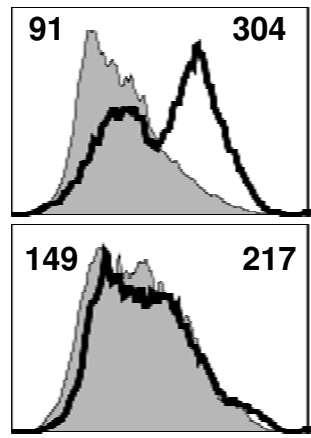

CD40

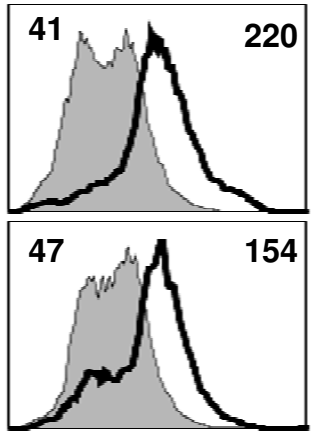

CD86

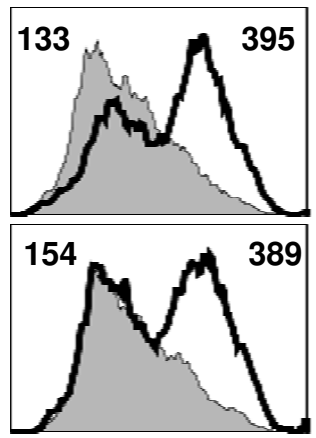

\section{Figure 4}

The conditioned medium of $P$. yoelii-infected erythrocytes inhibits DC maturation. (A) DCs were incubated alone (Control), in the presence of the conditioned media of uninfected (CM-RBCs) or P. yoelii-infected (CM-iRBCs) erythrocytes for $24 \mathrm{~h}$ followed by an additional $24 \mathrm{~h}$ in the absence (grey bars) or presence (black bars) of $100 \mathrm{ng} / \mathrm{ml}$ LPS. The CM-iRBCs was diluted $50 \%$ in medium or not (100\%). Results are expressed as the relative increase in MFI over DCs incubated in media alone. Error bars represent the standard deviation of 3 averaged independent experiments. *, indicates significant differences in DC surface expression when compared to DC incubated with CM-RBCs and stimulated with LPS. (B) DCs were incubated with either the conditioned medium of uninfected (CM-RBCs) or P. yoelii-infected (CM-iRBCs) erythrocytes in the presence or absence of $100 \mathrm{ng} / \mathrm{ml}$ LPS for $24 \mathrm{~h}$. (C) DCs were incubated in the presence of the conditioned medium of uninfected (CMRBCs) or P. yoelii-infected (CM-iRBCs) erythrocytes for $24 \mathrm{~h}$. DCs were washed and incubated in media alone for $24 \mathrm{~h}$ in the presence or absence of $100 \mathrm{ng} / \mathrm{ml}$ LPS. (B, C) FACS plots show CD40 or CD86 surface expression on DCs from control cultures (gray filled histogram) or incubated with LPS (black thick line). Mean fluorescent intensity (MFI) values are indicated in each plot for control and LPS stimulated. Each FACS plot is representative of one of at least 2 independent experiments.

\section{Discussion}

A number of studies have analysed the response of DCs incubated with human or mouse Plasmodium-infected erythrocytes in vitro or obtained from Plasmodium-infected mice ex vivo. Some of these studies found a normal DC maturation response [26-31,46], but others have found inhibition of DC maturation [16-21,23,25]. This apparent controversy has been resolved recently since it was found that the behavior of DCs is dependent on the strain of infecting parasite [24] and the subpopulation of DC analysed [42]. Additionally, the initial dose of parasite inoculated to induce infection and the time when DCs are analysed during infection influences the maturation state of DCs [42].

In this study, the DC response to a maturation stimulus in vivo in infected mice during late $P$. yoelii infection was analised. In these conditions, splenic DCs are found in an 


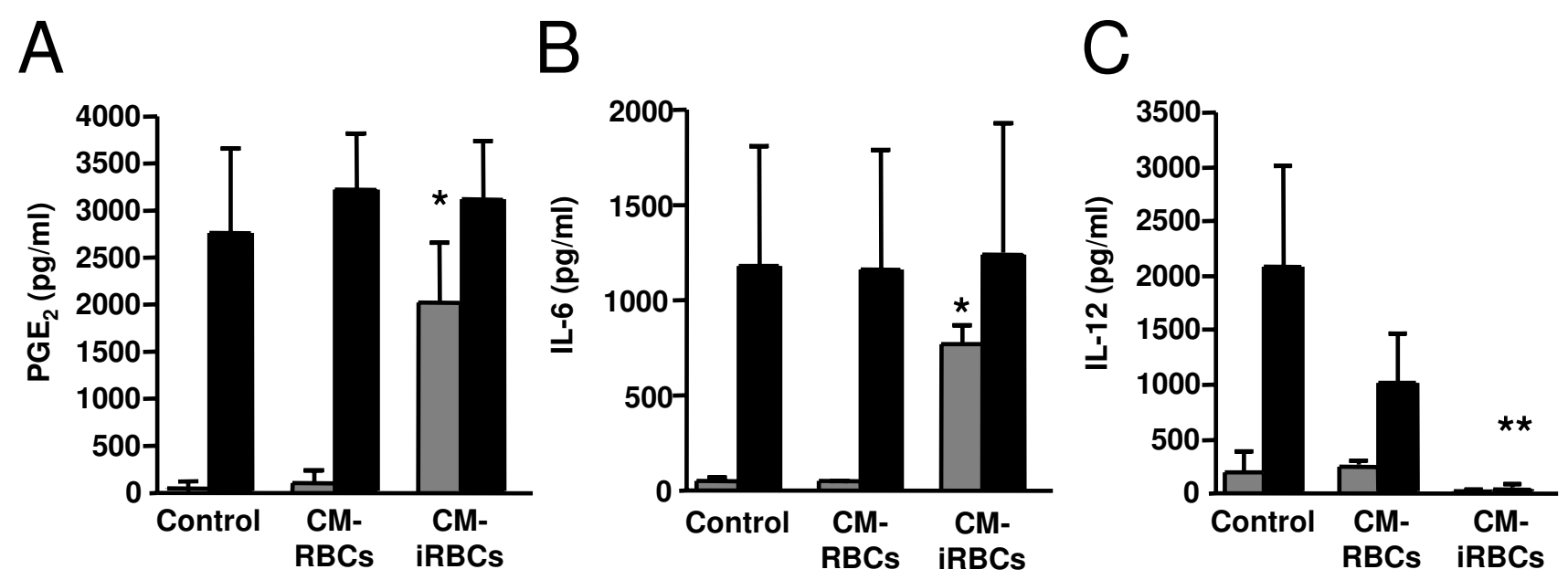

\section{Figure 5}

The conditioned medium of $\boldsymbol{P}$. yoelii-infected erythrocytes modulates DC cytokine production. (A-C) DCs were incubated with medium alone (control), the conditioned medium of uninfected (CM-RBCs) or P. yoelii-infected (CM-iRBCs) erythrocytes for $24 \mathrm{~h}$ in the absence (grey bars) or presence (black bars) of $100 \mathrm{ng} / \mathrm{ml} \mathrm{LPS}$. (A) PGE 2 , (B) IL-6 or (C) IL- I2 p70 concentrations were determined in the incubation medium by ELISA. Error bars represent the standard deviation of 3 averaged independent experiments. *, represents significant differences in IL-6 or PGE production by DCs in the presence of CMiRBCs when compared to production in the presence of CM-RBCs. **, represents significant differences in IL- I 2 production by DCs in the presence of CM-iRBCs with LPS when compared to production in the presence of CM-RBCs with LPS.

immature state and do not respond to LPS injection. It has been shown that DCs become refractory to TLR-mediated secretion of IL-12 and TNF during late $P$. yoelii infection [46]. This study also indicates that DCs are refractory to LPS stimulation. Since the DCs are found in an immature state, it suggests that there is a parasite-induced active inhibition rather than a tolerogenic effect caused by previous P. yoelii DC activation.

Recently we showed that Plasmodium-derived uric acid induces DC production of TNF [38]. Uric acid crystals have been identified as a danger signal that induces DC maturation [37]. It was found that in the presence of $P$. yoelii infected erythrocytes, DCs do not phenotypically mature in response to uric acid, which further broadens malaria induced suppression implications.

The inhibition of LPS-induced DC maturation was dependent on the dose of $P$. yoelii infected erythrocytes. This is consistent with findings observed using human DCs and P. falciparum [34] and suggests that this inhibitory effect would be most relevant during late infection when parasite loads are higher.

Using conditioned medium of $P$. yoelii-infected erythrocytes, it was determined that the P. yoelii-infected erythrocyte factor(s) that inhibits the LPS-induced phenotypic maturation of DCs was soluble. Upon further characteri- zation, this factor was found to be heat stable, smaller than $1 \mathrm{kDa}$ and non-hydrophobic. It is possible that this factor is produced by the parasite itself, or alternatively, Plasmodium could induce its production by host erythrocytes upon infection. It is not clear whether this factor would perform the same activity during infection in vivo since it requires a high concentration of infected erythrocytes to reach activity in vitro. However, infected erythrocytes accumulate in certain organs during infection [47], where local concentrations of the inhibitory factor may be reached.

It has been proposed that the inhibition of DC maturation is mediated by the binding of the P. falciparum protein PfEMP1, which is expressed on the surface of infected erythrocytes [48], to CD36 on the surface of DCs [16]. This was based on the observation that a non-adherent parasite cell line, which does not express PfEMP1, does not inhibit the maturation of DCs [16]. In addition, the authors observed that antibodies to CD36 inhibited maturation of DCs in a similar manner to $P$. falciparuminfected erythrocytes [35]. Conversely, it has been reported that $P$. falciparum modulation of DC phenotypic maturation is not contact dependent and does not required binding of CD36 and PfEMP1[34], suggesting that a soluble factor(s) is responsible for the effect. Since only a small subset of murine DCs express CD36 [49,50] and $P$. yoelii does not have genes homologous to PfEMP1 

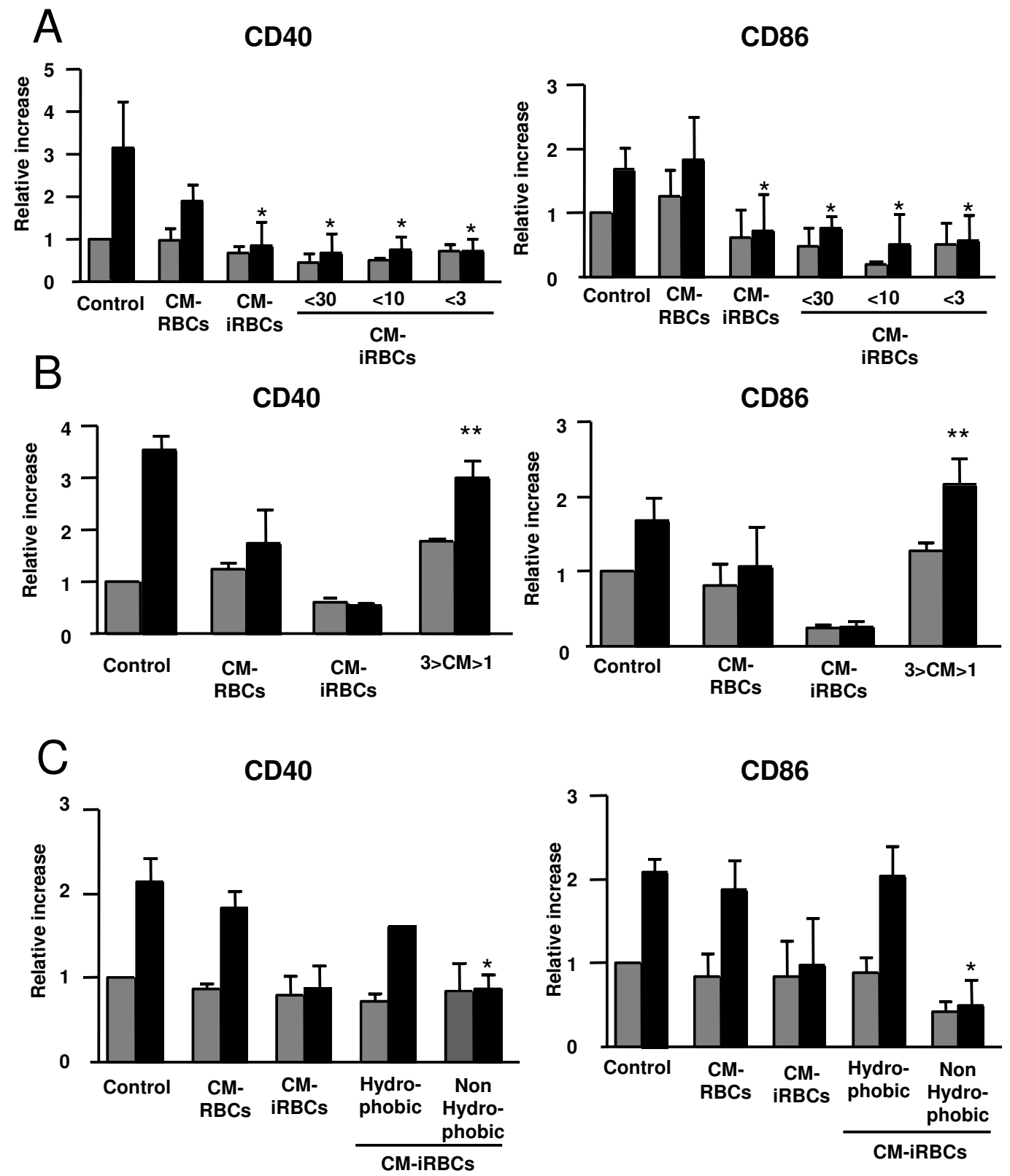

\section{Figure 6}

Characterization of the $\boldsymbol{P}$. yoelii soluble factor that inhibits DC maturation. (A-C) DCs were incubated alone (Control), in the presence of the conditioned media of uninfected (CM-RBCs) or P. yoelii-infected (CM-iRBCs) erythrocytes for $24 \mathrm{~h}$ followed by an additional $24 \mathrm{~h}$ in the absence (grey bars) or presence (black bars) of $100 \mathrm{ng} / \mathrm{ml}$ LPS. (A) Prior to incubation with DCs, conditioned medium of $P$. yoelii-infected erythrocytes (CM-iRBCs) was size fractioned using Centricon ${ }^{\circledR}$ filters to smaller than $30 \mathrm{kDa}(<30), 10 \mathrm{kDa}(<10)$ and smaller than $3 \mathrm{kDa}(<3)$. (B) Prior to incubation with DCs, molecules of smaller than I kDa were dialyzed out of the $P$. yoelii conditioned medium that was previously size fractioned to smaller than $3 \mathrm{kDa}$ $(3>C M>I)$. (C) Prior to incubation with DCs, The conditioned medium was fractionated based on hydrophobicity using Sep$\mathrm{Pak}^{\circledR}$ columns. (A-C) Results are expressed as the relative increase in MFI over DCs incubated in media alone. Error bars represent the standard deviation of 3 averaged independent experiments. *, represents significant differences in DC surface expression when compared to surface expression on DCs incubated with CM-RBCs and matured with LPS. **, represents significant differences in DC surface expression when compared to surface expression on DCs incubated with CM-iRBCs and matured with LPS. 
[51], the modulation of DCs by a soluble factor(s) derived from $P$. yoelii-infected erythrocytes is likely homologous to the later mechanism [34].

An immune suppressive role for hemozoin has been proposed $[52,53]$, including an inhibitory effect on DC maturation $[20,23,54]$. However, other reports propose hemozoin as an immune activator because of its ability as a purified extract to enhance DC maturation [55,56]. Recently, it was shown that parasite DNA that is associated with hemozoin after release from ruptured infected erythrocytes is responsible for the activation of DCs [57]. Haemozoin is not likely to be responsible for the DC inhibition observed in this work, since the size fractionation experiments showed that the inhibitory activity is smaller than $1 \mathrm{kDa}$ and the hemozoin pigment has a much higher molecular weight. No inhibitory activity on DCs of the fractions higher than $30 \mathrm{kDa}$ was found. Additionally, it was also shown that the inhibitory activity of the conditioned medium is not sensitive to DNase I treatment, excluding parasite DNA as a mediator of the DCs inhibitory activity.

DCs possess the capacity to secrete immune regulatory cytokines, such as IL-12, which is an important cytokine involved in the initiation of cellular immune responses [58]. It was observed that a soluble factor(s) of P. yoeliiinfected erythrocytes inhibits the LPS-induced production of IL-12 by DCs. It is not clear yet whether the same parasite-derived factor(s) is responsible for the inhibition of maturation and IL-12 secretion or these two effects are caused by different factors. Regardless, they both probably contribute to impaired $\mathrm{T}$ cell responses in the host, since the activation of Th1 cells requires both up-regulation of co-stimulatory molecules on DCs and secretion of IL-12 [58].

Despite parasite inhibition of DC phenotypic maturation, DCs still produce TNF, IL- 6 and PGE $_{2}$ in response to Plasmodium infected erythrocytes $[18,19,38,45]$. The $P$. yoelii factor that induces TNF, and at least part of the $\mathrm{PGE}_{2}$ and IL-6, was shown to be Plasmodium-derived hypoxanthine that is converted into uric acid [38]. Since TNF can induce the maturation of DCs and it was recently shown that systemic TNF in Plasmodium-infected mice can impair the DC function [25], it was tested whether hypoxanthine in the conditioned medium or uric acid produced after its degradation were responsible for the impaired maturation of DCs observed.

It was confirmed that Plasmodium-derived hypoxanthine degradation into uric acid is not responsible for the inhibition of maturation observed in this study. However, it is remarkable that Plasmodium appears to use another small, non-hydrophobic molecule(s) to modulate host DC responses.

Additionally, the $P$. yoelii conditioned medium induces $\mathrm{PGE}_{2}$ and IL-6 secretion from DCs, which are important immune mediators during Plasmodium infection. $\mathrm{PGE}_{2}$ produced during blood stage $P$. yoelii infection has a general $\mathrm{T}$ cell inhibitory activity and in particular inhibits protective $\mathrm{CD}^{+} \mathrm{T}$ cell responses against the liver stage [45]. While a specific role of DC IL-6 production during malaria is unknown, IL-6 is considered an important regulator of the transition from the innate to acquired immune responses and it may also influence DC maturation via the inhibition of nuclear factor kappa B (NFkB) [59]. It was shown that $P$. yoelii triggers the early secretion of $\mathrm{PGE}_{2}$ in DCs, which in turn induces the secretion of IL-6 later in these cells [19]. Secretion of IL-6 by DCs is in part caused by parasite-derived uric acid, but is in part independent of this pathway [38]. Therefore, the same parasite-derived factor(s) that is responsible for the inhibition of maturation could also contribute to uric acid independent IL- 6 secretion.

DCs play a pivotal role in the immune response to pathogens. Using the human malaria parasite P. falciparum, human DCs were observed to be modulated $[16,18,34]$. These findings were supported by field studies in children that showed a decrease in HLA-DR expression on peripheral DCs from children with acute $P$. falciparum malaria $[35,36]$. Furthermore, it was shown that severe P. falciparum infection increases the frequency of BDCA3+ myeloid DCs in the peripheral circulation was increased and the expression of HLA-DR was decreased when comparing children with acute malaria to healthy controls [36].

The findings presented in this study are consistent with those observed in the children with acute $P$. falciparum infection [35,36], with those observed using a human in vitro model $[16,18,34]$, and with those observed for murine late infections $[17,19,20,42,45,46]$. This study indicates that $P$. yoelii-infected erythrocytes inhibit the maturation of DCs at high densities and produce a soluble factor(s) responsible for this effect. During Plasmodium infection DCs receive stimulatory signals provided by parasite-derived molecules such as GPI [60], hemozoin-associated parasite DNA [57], elevated concentrations of Plasmodium-derived uric acid [38] and probably other molecules that have not been yet characterized. At the same time the parasite appears to release a soluble factor(s) that interferes with the maturation of DCs. It is possible that the balance between these effects is switched during the progression of infection, such that the inhibitory effect may be more active during late infection when parasite loads are higher. 


\section{Conclusion}

It was observed that $P$. yoelii infection interferes with the maturation of DCs both in vivo and in vitro. During late infection, $P$. yoelii inhibits the maturation of murine splenic DCs. In vitro, P. yoelii-infected erythrocytes inhibit the maturation of DCs in a dose-dependent manner and also modify their cytokine secretion pattern. A small, heatstable, non-hydrophobic molecule derived from $P$. yoeliiinfected erythrocytes is responsible for the inhibition of DC maturation.

\section{Authors' contributions}

JO, KW, CO and AR conceived the study, participated in its design and coordination and wrote the manuscript. All authors read and approved the final manuscript.

\section{Acknowledgements}

We thank Dr. Salim Merali for help with Sep-Pak purifications, Dabeiba Bernal-Rubio for help with murine infections and Kurt Wong for help with FACs analysis. This work was supported by American Heart Association Grant-in-Aid 0555742T and Burroughs Welcome Fund Award for Investigators in Pathogenesis of Infectious Disease to A.R. NIH training grant 5T32 Al 07180 to J.O.

\section{References}

I. Riley EM, Wahl S, Perkins DJ, Schofield L: Regulating immunity to malaria. Parasite Immunol 2006, 28:35-49.

2. Ho M, Webster HK, Looareesuwan S, Supanaranond W, Phillips RE, Chanthavanich $P$, Warrell DA: Antigen-specific immunosuppression in human malaria due to Plasmodium falciparum. J Infect Dis 1986, 153:763-77I.

3. Brasseur P, Agrapart M, Ballet IJ, Druilhe P, Warrell MJ, Tharavanij S: Impaired cell-mediated immunity in Plasmodium falciparuminfected patients with high-parasitemia and cerebral malaria. Clin Immunol Immunopathol I 983, 27:38-50.

4. Hviid L, Theander TG, Abu-Zeid YA, Abdulhadi NH, Jakobsen PH, Saeed BO, Jepsen S, Bayoumi RA, Jensen JB: Loss of cellular immune reactivity during acute Plasmodium falciparum malaria. FEMS Microbiol Immunol I99I, 3:219-227.

5. Goonewardene R, Carter R, Gamage CP, Del Giudice G, David PH, Howie S, Mendis KN: Human T cell proliferative responses to Plasmodium vivax antigens: evidence of immunosuppression following prolonged exposure to endemic malaria. Eur J Immunol 1990, 20:|387-|39|.

6. Whittle HC, Brown J, Marsh K, Greenwood BM, Seidelin P, Tighe H, Wedderburn L: T-cell control of Epstein-Barr virus-infected B cells is lost during $P$. falciparum malaria. Nature 1984, 3 I 2:449-450.

7. Mabey DC, Brown A, Greenwood BM: Plasmodium falciparum malaria and Salmonella infections in Gambian children. J Infect Dis 1987, 155:1319-1321.

8. Cook IF: Herpes zoster in children following malaria. J Trop Med Hyg 1985, 88:26I-264.

9. Greenwood BM, Bradley-Moore AM, Bryceson AD, Palit A: Immunosuppression in children with malaria. Lancet 1972, I:169-172.

10. Williamson WA, Greenwood BM: Impairment of the immune response to vaccination after acute malaria. Lancet 1978, I:I328-1329.

II. Martiney JA, Sherry B, Metz CN, Espinoza M, Ferrer AS, Calandra T, Broxmeyer HE, Bucala R: Macrophage migration inhibitory factor release by macrophages after ingestion of Plasmodium chabaudi- infected erythrocytes: possible role in the pathogenesis of malarial anemia. Infect Immun 2000, 68:2259-2267.

12. Ahvazi BC, Jacobs P, Stevenson MM: Role of macrophage-derived nitric oxide in suppression of lymphocyte proliferation during blood-stage malaria. J Leukoc Biol 1995, 58:23-3I.

13. Kumaratilake LM, Ferrante A: IL-4 inhibits macrophage-mediated killing of Plasmodium falciparum in vitro. A possible par- asite-immune evasion mechanism. I Immunol 1992 , 149:194-199.

14. Correa M, Narayanan PR, Miller HC: Suppressive activity of splenic adherent cells from Plasmodium chabaudi-infected mice. J Immunol 1980, I 25:749-754.

15. Warren HS, Weidanz WP: Malarial immunodepression in vitro: adherent spleen cells are functionally defective as accessory cells in the response to horse erythrocytes. Eur J Immunol I976, 6:816-819.

16. Urban BC, Ferguson DJ, Pain A, Willcox N, Plebanski M, Austyn JM, Roberts DJ: Plasmodium falciparum-infected erythrocytes modulate the maturation of dendritic cells. Nature 1999, 400:73-77.

17. Ocana-Morgner C, Mota MM, Rodriguez A: Malaria blood stage suppression of liver stage immunity by dendritic cells. J Exp Med 2003, 197:|43-15|.

18. Urban BC, Willcox N, Roberts DJ: A role for CD36 in the regulation of dendritic cell function. Proc Natl Acad Sci USA 200I, 98:8750-8755.

19. Carapau D, Kruhofer M, Chatalbash A, Orengo JM, Mota MM, Rodriguez A: Transcriptome profile of dendritic cells during malaria: CAMP regulation of IL-6. Cell Microbiol 2007, 9:1738-I752.

20. Millington OR, Di Lorenzo C, Phillips RS, Garside P, Brewer JM: Suppression of adaptive immunity to heterologous antigens during Plasmodium infection through hemozoin-induced failure of dendritic cell function. J Biol 2006, 5:5.

21. Pouniotis DS, Proudfoot O, Bogdanoska V, Scalzo K, Kovacevic S, Coppel RL, Plebanski M: Selectively impaired CD8+ but not CD4+ $T$ cell cycle arrest during priming as a consequence of dendritic cell interaction with Plasmodium-infected red cells. J Immunol 2005, I 75:3525-3533.

22. Wilson NS, Behrens GM, Lundie RJ, Smith CM, Waithman J, Young L, Forehan SP, Mount A, Steptoe RJ, Shortman KD, de Koning-Ward TF, Belz GT, Carbone FR, Crabb BS, Heath WR, Villadangos JA: Systemic activation of dendritic cells by Toll-like receptor ligands or malaria infection impairs cross-presentation and antiviral immunity. Nat Immunol 2006, 7:165-172.

23. Millington OR, Gibson VB, Rush CM, Zinselmeyer BH, Phillips RS, Garside $P$, Brewer JM: Malaria impairs $T$ cell clustering and immune priming despite normal signal I from dendritic cells. PLoS Pathog 2007, 3:1380-I387.

24. Wykes MN, Liu XQ, Beattie L, Stanisic DI, Stacey KJ, Smyth MJ, Thomas R, Good MF: Plasmodium strain determines dendritic cell function essential for survival from malaria. PLoS Pathog 2007, 3:e96.

25. Wykes MN, Liu XQ, Jiang S, Hirunpetcharat C, Good MF: Systemic tumor necrosis factor generated during lethal Plasmodium infections impairs dendritic cell function. J Immunol 2007, 179:3982-3987.

26. Ing R, Segura M, Thawani N, Tam M, Stevenson MM: Interaction of mouse dendritic cells and malaria-infected erythrocytes: uptake, maturation, and antigen presentation. J Immunol 2006, I 76:44|-450.

27. Leisewitz AL, Rockett KA, Gumede B, Jones M, Urban B, Kwiatkowski DP: Response of the splenic dendritic cell population to malaria infection. Infect Immun 2004, 72:4233-4239.

28. Luyendyk J, Olivas OR, Ginger LA, Avery AC: Antigen-presenting cell function during Plasmodium yoelii infection. Infect Immun 2002, 70:294I-2949.

29. Perry JA, Rush A, Wilson RJ, Olver CS, Avery AC: Dendritic cells from malaria-infected mice are fully functional APC. J Immunol 2004, 172:475-482.

30. Seixas E, Cross C, Quin S, Langhorne J: Direct activation of dendritic cells by the malaria parasite, Plasmodium chabaudi chabaudi. Eur J Immunol 200 I, 3 I:2970-2978.

31. Sponaas AM, Cadman ET, Voisine C, Harrison V, Boonstra A, O'Garra A, Langhorne J: Malaria infection changes the ability of splenic dendritic cell populations to stimulate antigen-specific T cells. J Exp Med 2006, 203: | 427- 1433.

32. Banchereau J, Briere F, Caux C, Davoust J, Lebecque S, Liu YJ, Pulendran B, Palucka K: Immunobiology of dendritic cells. Annu Rev Immunol 2000, | 8:767-8II.

33. Rescigno $M$, Borrow P: The host-pathogen interaction: new themes from dendritic cell biology. Cell 200I, 106:267-270. 
34. Elliott SR, Spurck TP, Dodin JM, Maier AG, Voss TS, Yosaatmadja F, Payne PD, McFadden GI, Cowman AF, Rogerson SJ, et al:: Inhibition of dendritic cell maturation by malaria is dose dependent and does not require Plasmodium falciparum erythrocyte membrane protein I. Infect Immun 2007, 75:362I-3632.

35. Urban BC, Mwangi T, Ross A, Kinyanjui S, Mosobo M, Kai O, Lowe B, Marsh K, Roberts DJ: Peripheral blood dendritic cells in children with acute Plasmodium falciparum malaria. Blood 200I, 98:2859-286I.

36. Urban BC, Cordery D, Shafi MJ, Bull PC, Newbold Cl, Williams TN, Marsh K: The frequency of BDCA3-positive dendritic cells is increased in the peripheral circulation of Kenyan children with severe malaria. Infect Immun 2006, 74:6700-6706.

37. Shi Y, Evans JE, Rock KL: Molecular identification of a danger signal that alerts the immune system to dying cells. Nature 2003, 425:5|6-52I.

38. Orengo JM, Evans JE, Bettiol E, Leliwa-Sytek A, Day KP, Rodriguez A: Plasmodium-induced inflammation by uric acid. PLoS Pathogens 2008, 4:e 10000I3.

39. Stockinger B, Zal T, Zal A, Gray D: B cells solicit their own help from T cells. J Exp Med 1996, I 83:891-899.

40. Bruna-Romero O, Rodriguez A: Dendritic cells can initiate protective immune responses against malaria. Infect Immun 200I, 69:5I73-5I76

41. Reis e Sousa C: Dendritic cells in a mature age. Nat Rev Immunol 2006, 6:476-483.

42. Wong KA, Rodriguez A: Plasmodium infection and endotoxic shock induce the expansion of regulatory dendritic cells. J Immunol 2008, 180:7| 6-726.

43. Guermonprez P, Valladeau J, Zitvogel L, Thery C, Amigorena S: Antigen presentation and $\mathbf{T}$ cell stimulation by dendritic cells. Annu Rev Immunol 2002, 20:62I-667.

44. Kantengwa S, Jornot L, Devenoges C, Nicod LP: Superoxide anions induce the maturation of human dendritic cells. Am J Respir Crit Care Med 2003, 167:43I-437.

45. Ocana-Morgner C, Wong KA, Lega F, Dotor J, Borras-Cuesta F, Rodriguez A: Role of TGF-beta and PGE2 in T cell responses during Plasmodium yoelii infection. Eur J Immunol 2007, 37:1562-1574.

46. Perry JA, Olver CS, Burnett RC, Avery AC: Cutting edge: the acquisition of TLR tolerance during malaria infection impacts T cell activation. J Immunol 2005, I 74:592I-5925.

47. Franke-Fayard B, Janse CJ, Cunha-Rodrigues M, Ramesar J, Buscher P, Que I, Lowik C, Voshol PJ, den Boer MA, van Duinen SG, Febbraio M, Mota MM, Waters AP: Murine malaria parasite sequestration: CD36 is the major receptor, but cerebral pathology is unlinked to sequestration. Proc Natl Acad Sci USA 2005, | 02: | |468-| | 473.

48. Kyes S, Horrocks $P$, Newbold $C$ : Antigenic variation at the infected red cell surface in malaria. Annu Rev Microbiol 200I, 55:673-707.

49. Schulz O, Pennington DJ, Hodivala-Dilke K, Febbraio M, Reis e Sousa $C$ : CD36 or alphavbeta3 and alphavbeta5 integrins are not essential for MHC class I cross-presentation of cell-associated antigen by CD8 alpha+ murine dendritic cells. J Immunol 2002, 168:6057-6065.

50. Belz GT, Vremec D, Febbraio M, Corcoran L, Shortman K, Carbone FR, Heath WR: CD36 is differentially expressed by CD8+ splenic dendritic cells but is not required for cross-presentation in vivo. J Immunol 2002, 168:6066-6070.

51. Carlton JM, Angiuoli SV, Suh BB, Kooij TW, Pertea M, Silva JC, Ermolaeva MD, Allen JE, Selengut JD, Koo HL, Peterson JD, Pop M, Kosack DS, Shumway MF, Bidwell SL, Shallom SJ, van Aken SE, Riedmuller SB, Feldblyum TV, Cho JK, Quackenbush J, Sedegah M, Shoaibi A, Cummings LM, Florens L, Yates JR, Raine JD, Sinden RE, Harris MA, Cunningham DA, Preiser PR, Bergman LW, Vaidya AB, van Lin LH, Janse C], Waters AP, Smith HO, White OR, Salzberg SL, Venter JC, Fraser CM, Hoffman SL, Gardner MJ, Carucci DJ: Genome sequence and comparative analysis of the model rodent malaria parasite Plasmodium yoelii yoelii. Nature 2002, 419:5|2-5I9.

52. Morakote N, Justus DE: Immunosuppression in malaria: effect of hemozoin produced by Plasmodium berghei and Plasmodium falciparum. Int Arch Allergy Appl Immunol I988, 86:28-34.

53. Scorza T, Magez S, Brys L, De Baetselier P: Hemozoin is a key factor in the induction of malaria-associated immunosuppression. Parasite Immunol 1999, 2 1:545-554.
54. Skorokhod OA, Alessio M, Mordmuller B, Arese P, Schwarzer E: Hemozoin (malarial pigment) inhibits differentiation and maturation of human monocyte-derived dendritic cells: a peroxisome proliferator-activated receptor-gamma-mediated effect. J Immunol 2004, I 73:4066-4074.

55. Coban C, Ishii KJ, Sullivan DJ, Kumar N: Purified malaria pigment (hemozoin) enhances dendritic cell maturation and modulates the isotype of antibodies induced by a DNA vaccine. Infect Immun 2002, 70:3939-3943.

56. Pichyangkul S, Yongvanitchit K, Kum-arb U, Hemmi H, Akira S, Krieg AM, Heppner DG, Stewart VA, Hasegawa H, Looareesuwan S, Shanks GD, Miller RS: Malaria blood stage parasites activate human plasmacytoid dendritic cells and murine dendritic cells through a Toll-like receptor 9-dependent pathway. J Immunol 2004, 172:4926-4933.

57. Parroche P, Lauw FN, Goutagny N, Latz E, Monks BG, Visintin A, Halmen KA, Lamphier M, Olivier M, Bartholomeu DC, Gazzinelli RT, Golenbock DT: Malaria hemozoin is immunologically inert but radically enhances innate responses by presenting malaria DNA to Toll-like receptor 9. Proc Natl Acad Sci USA 2007, 104:1919-1924.

58. Kapsenberg ML: Dendritic-cell control of pathogen-driven Tcell polarization. Nat Rev Immunol 2003, 3:984-993.

59. Jones SA: Directing transition from innate to acquired immunity: defining a role for IL-6. J Immunol 2005, I 75:3463-3468.

60. Gowda DC: TLR-mediated cell signaling by malaria GPIs. Trends Parasitol 2007, 23:596-604.
Publish with Bio Med Central and every scientist can read your work free of charge

"BioMed Central will be the most significant development for disseminating the results of biomedical research in our lifetime. "

Sir Paul Nurse, Cancer Research UK

Your research papers will be:

- available free of charge to the entire biomedical community

- peer reviewed and published immediately upon acceptance

- cited in PubMed and archived on PubMed Central

- yours - you keep the copyright

Submit your manuscript here:

http://www.biomedcentral.com/info/publishing_adv.asp
BioMedcentral 